\title{
Correction to: Detection of critically endangered marine species with dwindling populations in the wild using eDNA gives hope for sawfishes
}

\author{
Ramón Bonfil ${ }^{1,2}$ (1) - Paola Palacios-Barreto ${ }^{1,3} \cdot$ Oscar Uriel Mendoza Vargas ${ }^{1} \cdot$ Melina Ricaño-Soriano ${ }^{1}$. \\ Píndaro Díaz-Jaimes ${ }^{3}$
}

Published online: 23 April 2021

(c) Springer-Verlag GmbH Germany, part of Springer Nature 2021

\section{Correction to: Marine Biology (2021) 168:60 \\ https://doi.org/10.1007/s00227-021-03862-7}

In the original publication of the article, the last author affiliation has been changed to Laboratorio de Genética de Organismos Acuáticos. Instituto de Ciencias del Mar y Limnología, Universidad Nacional Autónoma de México, Mexico CDMX 04510, México.

The original article has been updated.

Publisher's Note Springer Nature remains neutral with regard to jurisdictional claims in published maps and institutional affiliations.

The original article can be found online at https://doi.org/10.1007/ s00227-021-03862-7.

Ramón Bonfil

ramon.bonfil@oceanosvivientes.org

1 Océanos Vivientes AC, Mexico CDMX 04380, México

2 Present Address: Instituto de Ciências do Mar, Universidade Federal do Ceará, Fortaleza CE 60165-081, Brazil

3 Laboratorio de Genética de Organismos Acuáticos. Instituto de Ciencias del Mar y Limnología, Universidad Nacional Autónoma de México, Mexico CDMX 04510, México 